\title{
Green synthesis of silver nanoparticles in aloe vera plant extract prepared by a hydrothermal method and their synergistic antibacterial activity
}

\author{
Patcharaporn Tippayawat ${ }^{\text {Corresp., }}{ }^{1,2}{ }^{\text {, Nutthakritta Phromviyo }}{ }^{3}$, Parichart Boueroy ${ }^{4}$, Apiwat Chompoosor ${ }^{5,6}$ \\ 1 Division of Clinical Microbiology/ Faculty of Associated Medical Sciences, Khon Kaen University, Khon Kaen, Thailand \\ 2 The Center for Research \& Development of Medical Diagnostic Laboratories/ Faculty of Associated Medical Sciences, Khon Kaen University, Khon Kaen, \\ Thailand \\ 3 Materials Science and Nanotechnology Program/ Faculty of Science, Khon Kaen University, Khon Kaen, Thailand \\ 4 Department of Microbiology/ Faculty of Medicine, Khon Kaen University, Khon Kaen, Thailand \\ 5 Department of Chemistry/ Faculty of Science, Ramkhamhaeng University, Bangkok, Thailand \\ 6 Integrated Nanotechnology Research Center (INRC), Khon Kaen University, Khon Kaen, Thailand \\ Corresponding Author: Patcharaporn Tippayawat \\ Email address: patchatip@kku.ac.th
}

Background: There is worldwide interest in silver nanoparticles (AgNPs) synthesized by various chemical reactions for use in applications exploiting their antibacterial activity, even though these processes exhibit a broad range of toxicity in vertebrates and invertebrates alike. To avoid the chemical toxicity, biosynthesis (green synthesis) of metal nanoparticles is proposed as a cost-effective and environmental friendly alternative. Aloe vera leaf extract is a medicinal agent with multiple properties including an antibacterial effect. Moreover the constituents of aloe vera leaves include lignin, hemicellulose, and pectins which can be used in the reduction of silver ions to produce as AgNPs@aloe vera (AgNPs@AV) with antibacterial activity. Methods: AgNPs were prepared by an eco-friendly hydrothermal method using an aloe vera plant extract solution as both a reducing and stabilizing agent. AgNPs@AV were characterized using XRD and SEM. Additionally, an agar well diffusion method was used to screen for antimicrobial activity. MIC and MBC were used to correlate the concentration of AgNPs@AV its bactericidal effect. SEM was used to investigate bacterial inactivation. Then the toxicity with human cells was investigated using an MTT assay. Results: The synthesized AgNPs were crystalline with sizes of 70.70 $\pm 22-192.02 \pm 53 \mathrm{~nm}$ as revealed using XRD and SEM. The sizes of AgNPs can be varied through alteration of times and temperatures used in their synthesis. These AgNPs were investigated for potential use as an antibacterial agent to inhibit pathogenic bacteria. Their antibacterial activity was tested on $S$. epidermidis and $P$. aeruginosa. The results showed that AgNPs had a high antibacterial which depended on their synthesis conditions, particularly when processed at $100{ }^{\circ} \mathrm{C}$ for $6 \mathrm{~h}$ and $200{ }^{\circ} \mathrm{C}$ for $12 \mathrm{~h}$. The cytotoxicity of AgNPs was determined using human PBMCs revealing no obvious cytotoxicity. These 
results indicated that AgNPs@AV can be effectively utilized in pharmaceutical, biotechnological and biomedical applications. Discussion: Aloe vera extract was processed using a green and facile method. This was a hydrothermal method to reduce silver nitrate to AgNPs@AV. Varying the hydrothermal temperature provided the fine spherical shaped nanoparticles. The size of the nanomaterial was affected by its thermal preparation. The particle size of AgNPs could be tuned by varying both time and temperature. A process using a pure AG phase could go to completion in $6 \mathrm{~h}$ at $200{ }^{\circ} \mathrm{C}$, whereas reactions at lower temperatures required longer times. Moreover, the antibacterial effect of this hybrid nanomaterial was sufficient that it could be used to inhibit pathogenic bacteria since silver release was dependent upon its particle size. The high activity of the largest AgNPs might have resulted from a high concentration of aloe vera compounds incorporated into the AgNPs during hydrothermal synthesis. 
1 Green synthesis of silver nanoparticles in aloe vera plant extract prepared by a hydrothermal

2 method and their synergistic antibacterial activity

3 Patcharaporn Tippayawat ${ }^{1,2 *}$, Nutthakritta Phromviyo ${ }^{3}$, Parichart Boueroy ${ }^{4}$, Apiwat

4 Chompoosor ${ }^{5,6^{*}}$

$5{ }^{1}$ Division of Clinical Microbiology, Faculty of Associated Medical Sciences, Khon Kaen University,

6 Khon Kaen, 40002, Thailand

$7 \quad{ }^{2}$ The Center for Research \& Development of Medical Diagnostic Laboratories, Faculty of Associated

8 Medical Sciences, Khon Kaen University, Khon Kaen, Thailand

9 Materials Science and Nanotechnology Program, Faculty of Science, Khon Kaen University,

10 Khon Kaen, 40002, Thailand

$11{ }^{4}$ Department of Microbiology, Faculty of Medicine, Khon Kaen University, Khon Kaen, 40002, Thailand

$12{ }^{5}$ Department of Chemistry, Faculty of Science, Ramkhamhaeng University, Ramkhamhaeng Road, Hua

13 mark, Bangkapi, Bangkok, 10240, Thailand

$14{ }^{6}$ Integrated Nanotechnology Research Center (INRC), Khon Kaen University,

15 Khon Kaen, 40002, Thailand

16

17 Corresponding authors:

18 Patcharaporn Tippayawat ${ }^{1,2}$

19 Department of Clinical Microbiology, AMS, Khon Kaen University, 123 Mittraparb Road, Muang, Khon

20 Kaen, Thailand, 40002

21 Email address: patchatip@kku.ac.th

22 Apiwat Chompoosor 5,6

23 Department of Chemistry, Faculty of Science, Ramkhamhaeng University, Ramkhamhaeng Road, Hua

24 mark, Bangkapi, Bangkok, Thailand, 10240

25 Email address: apiwat@ru.ac.th 


\section{Abstract}

28 Background: There is worldwide interest in silver nanoparticles (AgNPs) synthesized by various chemical reactions for use in applications exploiting their antibacterial activity, even though these processes exhibit a broad range of toxicity in vertebrates and invertebrates alike. To avoid the chemical toxicity, biosynthesis (green synthesis) of metal nanoparticles is proposed as a costeffective and environmental friendly alternative. Aloe vera leaf extract is a medicinal agent with multiple properties including an antibacterial effect. Moreover the constituents of aloe vera leaves include lignin, hemicellulose, and pectins which can be used in the reduction of silver ions to produce as AgNPs@aloe vera (AgNPs@AV) with antibacterial activity.

Methods: AgNPs were prepared by an eco-friendly hydrothermal method using an aloe vera plant extract solution as both a reducing and stabilizing agent. AgNPs@AV were characterized using XRD and SEM. Additionally, an agar well diffusion method was used to screen for antimicrobial activity. MIC and MBC were used to correlate the concentration of AgNPs@AV its bactericidal effect. SEM was used to investigate bacterial inactivation. Then the toxicity with human cells was investigated using an MTT assay.

Results: The synthesized AgNPs were crystalline with sizes of $70.70 \pm 22-192.02 \pm 53 \mathrm{~nm}$ as revealed using XRD and SEM. The sizes of AgNPs can be varied through alteration of times and temperatures used in their synthesis. These AgNPs were investigated for potential use as an antibacterial agent to inhibit pathogenic bacteria. Their antibacterial activity was tested on $S$. epidermidis and $P$. aeruginosa. The results showed that AgNPs had a high antibacterial which depended on their synthesis conditions, particularly when processed at $100^{\circ} \mathrm{C}$ for $6 \mathrm{~h}$ and $200{ }^{\circ} \mathrm{C}$ 
49 cytotoxicity. These results indicated that AgNPs@AV can be effectively utilized in 50 pharmaceutical, biotechnological and biomedical applications.

51 Discussion: Aloe vera extract was processed using a green and facile method. This was a 52 hydrothermal method to reduce silver nitrate to AgNPs@AV. Varying the hydrothermal 53 temperature provided the fine spherical shaped nanoparticles. The size of the nanomaterial was 54 affected by its thermal preparation. The particle size of AgNPs could be tuned by varying both 55 time and temperature. A process using a pure AG phase could go to completion in $6 \mathrm{~h}$ at $200{ }^{\circ} \mathrm{C}$, 56 whereas reactions at lower temperatures required longer times. Moreover, the antibacterial effect 57 of this hybrid nanomaterial was sufficient that it could be used to inhibit pathogenic bacteria since 58 silver release was dependent upon its particle size. The high activity of the largest AgNPs might have resulted from a high concentration of aloe vera compounds incorporated into the AgNPs

60 during hydrothermal synthesis.

\section{Introduction}

63

Silver nanoparticles (AgNPs) have been extensively studied for many decades due to their unique features and wide range of applications. Their uses include catalysis (Pradhan, Pal \& Pal, 2002), biosensing (Anker et al., 2008), imaging (Lee \& El-Sayed, 2006), and antibacterial activity (Morones et al., 2005; Rai, Yadav \& Gade, 2009). Among these applications, antibacterial activities have gained much attention because they potentially offer a solution to the problem of antibiotic resistance (Cho et al., 2005). There are a variety of methods to synthesize AgNPs including physical and chemical methods (Chudasama et al., 2010). Chemical reduction of silver ions using sodium borohydride (Zhang et al., 2000), hydrazine (Taleb, Petit \& Pileni, 1997), ascorbic acid (Lee et al., 2004), trisodium citrate (Sun Mayers \& Xia, 2003), and polyols (Sun \& 
72 Xia, 2002) were reported and are considered well-established methods. Although chemical routes

73 are effective, these methods may suffer from toxicity due to the chemicals used and the difficulty

74 in removing them. Additionally, chemical reagents used in these methods are hazardous to the

75 environment (Nabikhan et al., 2010). To avoid the toxicity of chemicals, green synthesis was

76 developed (Sharma, Yngard \& Lin, 2009). This method of biosynthesis of metal nanoparticles has

77 been proposed as a cost-effective and environmental friendly way of fabricating these materials.

78 Synthesis of AgNPs employing either microorganisms or plant extracts has emerged as an

79 alternative approach. These biosynthetic methods have a numbers of benefits. They are simple,

80 cost-effective, give high yields, and are environmentally friendly (Zhang et al., 2013). Plant

81 extracts have reportedly been used in the preparation of AgNPs (Sun et al., 2014). Aloe vera leaves

82 have been used as medicinal plants since they possess anti-inflammatory activity, UV protection,

83 anti-arthritic properties, promote wound and burn-healing, and have antibacterial properties

84 (Chandran et al., 2006; Feng et al., 2000; Reynolds \& Dweck, 1999; Vazquez et al., 1996). There

85 are a number of biologically active constituents in aloe vera leaves. These include lignin,

86 hemicellulose, pectins which can be used in the reduction of silver ions (Emaga et al., 2008). It is

87 believed that the large enzymes and proteins in aloe vera extract are weakly bound to silver ions

88 and function as a complexing agent. Due to their low cost and environmentally friendly nature

89 coupled with their reducing properties, we selected aloe vera as the reducing and stabilizing agent

90 to prepare AgNPs and test their antibacterial activity.

91 In this study, we report a one-step hydrothermal method to prepare silver nanoparticles. Reduction

92 of $\mathrm{Ag}^{+}$ions to $\mathrm{Ag}^{0}$ nanoparticles was done in a medium of aloe vera extract in which no extra

93 reducing agent was used. The resulting AgNPs can be obtained in large quantities. The sizes of

94 AgNPs were found to be in a range of 70.70-192.02 nm and controllable by varying temperature 
95 and time conditions of the hydrothermal process. Further, the resulting AgNPs were found to be

96 effective against gram-positive (Streptococcus epidermidis) and gram-negative (Pseudomonas

97 aeruginosa). Therefore, this work has shown the use of naturally occurring compounds to be a

98 reducing and stabilizing agent. This method is considered green synthesis. The resulting silver

99 nanoparticles showed a synergism of aloe vera and silver nanoparticles on bactericidal effect. This

100 hybrid nanomaterial provides an alternative material for using in antibacterials.

101

102 Materials and Methods

103 In this study, silver nitrate, $\mathrm{AgNO}_{3}$ (Sigma-Aldrich Chemicals, USA) and aloe vera plant extract

104 were used as the starting materials. The aloe vera extract solution was prepared using $50 \mathrm{~g}$ of aloe

105 vera leaves that had been rinsed with deionized water and finely cut into small pieces. The chopped

106 aloe vera leaves were boiled in a $50 \mathrm{~mL}$ of deionized water for 20 minutes and allowed to cool.

107 The cooled leaf broth was filtered and stored in a refrigerator at $4{ }^{\circ} \mathrm{C}$. The resulting extract was

108 used as an aloe vera extract solution.

109 Synthesis of AgNPs and Characterization of AgNPs

110 In the preparation of $\mathrm{AgNPs}$ samples, $\mathrm{AgNO}_{3}(0.3 \mathrm{~mol})$ was first dissolved in $20 \mathrm{ml}$ of deionized

111 water and mixed with $20 \mathrm{ml}$ of aloe vera extract solution under vigorous stirring at room

112 temperature for 30 minutes. The mixtures were added to sealed Teflon-lined vessels of $100 \mathrm{~mL}$

113 capacity (Parr, USA), which were heated and maintained at various time and temperature

114 conditions, and then gradually cooled to room temperature. A gray precipitate was collected by

115 filtration and washed with deionized water several times, and finally dried in air at $60{ }^{\circ} \mathrm{C}$ for $6 \mathrm{~h}$.

116 The crystal phase analysis of the AgNPs powders was conducted using X-ray diffraction (XRD)

117 (PW3710, the Netherlands) with $\mathrm{CuK} \alpha$ radiation $(\lambda=0.15406 \mathrm{~nm})$. The particle sizes and 
118 morphology of the prepared AgNPs samples were characterized using scanning electron

119 microscopy (SEM) (LEO SEM 1450VP, UK) and transmission electron microscopy (TEM) (FEI

$1205022 / 22$ Tecnai G2 20 S-Twin, CR). The UV-visible absorbance of the AgNPs was measured

121 using UV-1800 (Shimadzu, Japan).

122

123 Antibacterial Tests and Cytotoxicity Test

124 Well diffusion method

125 The antibacterial activity of AgNPs prepared under different hydrothermal processing conditions

126 were tested against gram-negative P. aeruginosa (Pseudomonas aeruginosa, ATCC27803) and

127 gram-positive S. epidermidis (Staphylococcus epidermidis, ATCC35984) using an agar well

128 diffusion method. The organisms were sub-cultured in nutrient broth at $37{ }^{\circ} \mathrm{C}$ and incubated

129 overnight. After that, Nutrient Agar (Merck) was swabbed with the respective sub-cultures $\left(1 \times 10^{8}\right.$

$130 \mathrm{CFU} / \mathrm{ml}$ ). Specimens containing AgNPs were then arranged on the swabbed agar surface and

131 incubated at $37^{\circ} \mathrm{C}$ for $24 \mathrm{~h}$. The results were read by measuring the diameter of the inhibition zone

132 (mm). The experiments were done in triplicate.

\section{Scanning electron microscopy (SEM)}

134 Scanning electron microscopy of control cells and AgNPs treated cells $(0.04 \mathrm{mg} / \mathrm{mL})$ was

135 performed to investigate the antibacterial activity. Each bacterial culture was prepared as described

136 above and then pipetted into a 6-well plate with and without AgNPs prior to covering the wells

137 with glass slides. After incubating at $37{ }^{\circ} \mathrm{C}$ overnight, the glass slides were removed and gently

138 washed with phosphate buffer saline 3 times before dehydration in an alcohol series using

139 concentrations of $25 \%, 50 \%, 75 \%, 90 \%$ and $100 \%$ ethanol in distilled water. The slides were left 
140 in each concentration for 20 minutes. They were then air dried and kept in a desiccator until

141 analysis.

142 Minimum inhibitory concentration (MIC) and minimal bactericidal concentration (MBC)

143 A microdilution method was used to indicate the bactericidal effect of AgNPs. A suspension of

$1441 \times 10^{8} \mathrm{CFU} / \mathrm{ml}$ of bacteria in nutrient broth was prepared as described above. The antibacterial

145 solutions were prepared using serial two-fold (1:2) dilutions of AgNPs in concentrations ranging

146 from 0.04 to $0.00008 \mathrm{mg} / \mathrm{mL}$ and incubated at $37{ }^{\circ} \mathrm{C}$ for $24 \mathrm{~h}$. In the range of sample turbidity, the

147 MIC of the samples could not be determined to identify the lowest concentration of antibacterial

148 agent that inhibits $99 \%$ of the growth of the bacteria. A microdilution measurement was done in

149 triplicate to confirm the value of MIC for each tested bacteria. As such, the MBC was measured

150 after MIC determination. In this assay, $10 \mu \mathrm{l}$ from all concentrations of AgNPs were pipetted onto

151 nutrient agar plates and incubated at $37^{\circ} \mathrm{C}$ for $24 \mathrm{~h}$. The $\mathrm{MBC}$ endpoint was interpreted at the

152 lowest concentration of antibacterial agent killing $100 \%$ of the initial bacterial population.

\section{Cytotoxicity Test}

154 The AgNP samples produced at $100^{\circ} \mathrm{C}$ for $6 \mathrm{~h}$ and $200^{\circ} \mathrm{C}$ for $12 \mathrm{~h}$ were tested for their cytotoxicity

155 using the MTT (3-4,5-dimethylthiazol-2-yl)-2,5-diphenyltetrazolium bromide) assay. Human

156 peripheral blood mononuclear cells (PBMCs) from the leftover buffy coat were suspended into

157 complete 1640 RPMI (supplemented with 10\% fetal bovine serum, $2 \mathrm{mM} \mathrm{L-glutamine,} 100 \mathrm{unit} / \mathrm{ml}$

158 penicillin and $100 \mu \mathrm{g} / \mathrm{ml}$ streptomycin) in a 96-well plate at a density of $10^{5}$ cells/well. This was

159 done prior to exposure to AgNPs dissolved in RPMI to make a stock concentration at $0.04 \mathrm{mg} / \mathrm{mL}$.

160 The stock solution was used to generate serial two-fold dilution at 4 concentrations, i.e., 0.02, 0.01,

1610.005 , and $0.0025 \mathrm{mg} / \mathrm{mL}$. Then, the cells were incubated at $37{ }^{\circ} \mathrm{C}$ in a fully humidified, $5 \% \mathrm{CO}_{2}$

162 air atmosphere for $48 \mathrm{~h}$. The test samples were removed from the cell cultures and the cells were 
163 reincubated for a further $24 \mathrm{~h}$ in fresh medium. They were then tested using the MTT assay.

164 Briefly, $50 \mu \mathrm{l}$ of MTT in phosphate buffered saline at $5 \mathrm{mg} / \mathrm{ml}$ was added into a medium in each

165 well and the cells were incubated for $4 \mathrm{~h}$. The medium and MTT were then gently aspirated from

166 the wells and solubilized in formazan with $200 \mu \mathrm{l}$ of DMSO and $25 \mu \mathrm{l}$ of Sorensen's Glycine

167 buffer, $\mathrm{pH}$ 10.5. The optical density was read with a microplate reader at a wavelength of $560 \mathrm{~nm}$.

168 The average of 3 wells was used to determine the mean of each point. Then $\%$ survival of the cells

169 was calculated. For each test sample, the data was used to determine the concentration of sample

170 required to kill $50 \%\left(\mathrm{IC}_{50}\right)$ of the cells compared to that of the controls. A dose-response curve

171 was derived from 5 concentrations in the test range using 3 wells per concentration.

172

173 Results

174 Characterization of Silver Nanoparticles

175 The morphology of AgNPs prepared at different reaction temperatures and times was examined

176 using SEM. The result showed SEM images of AgNPs obtained by the reduction of $\mathrm{AgNO}_{3}$ with

177 aloe vera plant extract (Fig. 1). It was found that the reaction time and temperature had significant

178 effects on the formation of Ag nanostructures. AgNPs were observed as spherical particles with

179 the sizes between $70.7-192.02 \mathrm{~nm}$, moreover the sizes of the materials were significantly affected

180 by their preparation temperature as presented in Table 1 . At $6 \mathrm{~h}$, the AgNPs showed the sizes of

$18170.70 \pm 23,79.47 \pm 22$, and $161.66 \pm 53 \mathrm{~nm}$ prepared at $100{ }^{\circ} \mathrm{C}, 150{ }^{\circ} \mathrm{C}$ and $200{ }^{\circ} \mathrm{C}$, respectively.

182 At $12 \mathrm{~h}$, the AgNPs showed sizes of $95.25 \pm 23,149.55 \pm 47$ and $192.02 \pm 53 \mathrm{~nm}$ prepared at 100

$183{ }^{\circ} \mathrm{C}, 150^{\circ} \mathrm{C}$ and $200^{\circ} \mathrm{C}$, respectively. Furthermore, TEM image of AgNPs prepared at $100{ }^{\circ} \mathrm{C}$ for 6

$184 \mathrm{~h}$ indicating that the size of AgNPs was in good agreement with SEM results, UV-vis absorption

185 spectra of AgNPs showed that the maximum absorption was found at $420 \mathrm{~nm}$ and was attributed 
186 to the surface plasmon resonance of AgNPs (Figs. 2A and 2B). The XRD patterns of AgNPs

187 resulted from using the above 3 hydrothermal conditions (Figs. 3A and 3B). All of the main peaks

188 were indexed as AgNPs with the face centered cubic (fcc) lattice of silver, as shown in the standard

189 data (JCPDS file No.01-071-4613). The diffraction peaks at $2 \theta$ degree of 38.2, 44.3, 64.5 and 77.1

190 corresponded to the (111), (200), (220), and (311) planes, respectively. A pure phase of Ag was

191 only obtained at a temperature of $200{ }^{\circ} \mathrm{C}$ for $6 \mathrm{~h}$. The chemical reaction to form a pure phase at

192100 and $150^{\circ} \mathrm{C}$ for $6 \mathrm{~h}$ was incomplete because reaction at such a low temperature usually requires

193 a longer time (Fig. 3A). The existence of $\mathrm{Ag}_{2} \mathrm{O}$ was shown at the peak at around 31.9 (Liu et al.,

194 2010). The result showed a pure Ag phase in all the samples prepared using hydrothermal

195 conditions for $12 \mathrm{~h}$ (Fig. 3B).

\section{Antibacterial Effects}

197 An advantage of silver nanoparticles is that they are known to have an antibacterial effect (Rai et 198 al., 2012). However, the AgNPs formed during the aloe vera hydrothermal method, AgNPs@AV, 199 need to have bioactive functions. It is especially important to understand the functional effects on 200 microorganisms in order to develop novel antibacterial agents. To demonstrate this activity, 201 AgNPs were studied for their bactericidal effect against pathogenic gram-positive S. epidermidis

202 and gram-negative $P$. aeruginosa. These two strains are the opportunistic bacteria causing of 203 nosocomial infection, moreover there are the virulent factors involving with antibiotic resistance 204 (Otto 2009; Livermore 2002). Thus, our new product might be a material of choice to apply in 205 antimicrobial activity instead of antibiotics. This was done using a qualitative antibacterial well 206 diffusion assay and studying AgNPs interaction with bacteria using SEM. Quantitative 207 antibacterial concentrations were evaluated by determining the minimum bactericidal 208 concentration $(\mathrm{MBC})$. It was observed that the inhibition zones of both pathogens were significant 
209 for $0.1 \mathrm{mg} / \mathrm{mL}$ AgNPs prepared at $100^{\circ} \mathrm{C}$ for $6 \mathrm{~h}, 150{ }^{\circ} \mathrm{C}$ and $200^{\circ} \mathrm{C}$ for $12 \mathrm{~h}$ compared with the

210 control (Fig. 4 and Table 1). The AgNPs synthesized under different conditions provided varying

211 bactericidal effects. Then, the effects of two AgNPs@AV samples including those prepared at 100

$212{ }^{\circ} \mathrm{C}$ for $6 \mathrm{~h}$ and $200{ }^{\circ} \mathrm{C}$ for $12 \mathrm{~h}$, were selected for further studies using SEM and MBC. The

213 interaction of AgNPs and microorganisms was shown using SEM. The result indicated the cell

214 membrane changed when contacted with the nanoparticles (Fig. 5). This was particularly true for

215 gram-negative bacteria, showing a thin layer of membrane and having pores. Subsequently, MBC

216 of the bacterial concentration at $10^{8} \mathrm{CFU} / \mathrm{ml}$ was determined for both $S$. epidermidis and $P$.

217 aeruginosa. This demonstrated the lowest concentration of nanoparticles with bactericidal effect

218 was $0.01 \mathrm{mg} / \mathrm{mL}$ for AgNPs fabricated at $100{ }^{\circ} \mathrm{C}$ for $6 \mathrm{~h}$ and $200{ }^{\circ} \mathrm{C}$ for $12 \mathrm{~h}$ against $10^{8} \mathrm{CFU} / \mathrm{ml}$

219 S. epidermidis. The corresponding concentrations was $0.0025 \mathrm{mg} / \mathrm{mL}$ for AgNPs fabricated at 100

$220{ }^{\circ} \mathrm{C}$ for $6 \mathrm{~h}$ and $0.00125 \mathrm{mg} / \mathrm{mL}$ for those formed at $200{ }^{\circ} \mathrm{C}$ for $12 \mathrm{~h}$ against $10^{8} \mathrm{CFU} / \mathrm{ml} P$.

221 aeruginosa. Moreover, the microbicidal activity of nanoparticles provided high efficiency within

2222 months. At the lower AgNPs concentrations, clearly there was an effect on the lethality against

223 gram negative-bacteria whereas higher concentrations were needed to control gram-positive

224 bacteria.

225 Cytotoxicity Evaluation

226 To determine the cytotoxicity of AgNPs@AV on human cells, PBMCs were tested using the MTT 227 assay. The result was calculated as \%survival of the cells cultured with samples at concentrations 228 of $0.04,0.02,0.01,0.005$, and $0.0025 \mathrm{mg} / \mathrm{mL}$ of $100{ }^{\circ} \mathrm{C}$ for $6 \mathrm{~h}$ and $200{ }^{\circ} \mathrm{C}$ for $12 \mathrm{~h}$ processed 229 AgNPs@AV. The \%survival of the cells in less $0.0025 \mathrm{mg} / \mathrm{mL}$ of both nanoparticles was 230 significantly higher than 50\% which confirms that these AgNPs@AVs were non-toxic to human 231 PBMCs. Nanoparticles produced by green synthesis can be useful in biomedical applications. 


\section{Discussion}

234 Recently, there has been increasing study of AgNPs synthesis to develop several applications such

235 as catalysis, biosensing, imaging, and antibacterial activity. Green synthesis is an alternative

236 method developed to produce metal nanoparticles by using natural compounds or plant

237 components. These are environmentally friendly processes that avoid the toxicity of chemicals.

238 Algae, bacteria, fungi and plants have been used to synthesize NPs without the need for additional

239 reducing and stabilizing agents. Plant extracts contain functional substances, including cyclic

240 peptides, sorbic acid, citric acid, euphol, polyhydroxy limonoids, ascorbic acid, retinoic acid,

241 tannins, ellagic acid, and gallic acid, among others, are strongly believed to play a crucial role in

242 the bioreduction and stabilization of nanoparticles (Rajan et al., 2015). These processes seem

243 facile, safe, low cost, and ecofriendly, eliminating the elaborate process of maintaining aseptic cell

244 cultures and are suitable for large scale production. Therefore, this study focused on the

245 biosynthesis of AgNPs with plant extracts of aloe vera leaves. Zhang et al. (2010) speculated that

246 the hydroquinones in the aloe vera plant extract act as the reducing agents. Additionally, the

247 spherical shape of AgNPs was governed by the weaker binding of proteins in the solution leading

248 to the isotropic growth of the AgNPs. Here, the hydrothermal process was applied to AgNPs

249 synthesis in which time and temperature had an effect on the resulting crystalline structure of 250 AgNPs. High temperature and pressure are necessary to facilitate the reduction processes (Liu et 251 al., 2012). Nucleation and the growth of AgNPs depend on the reaction temperature. Additionally,

252 capping agents also play a role in the synthesis of nanoparticles. Selective interaction of capping

253 agents may lead to anisotropic crystalline growth. Poly (vinyl) pyrrolidoneis are widely used to

254 synthesize nanorods due to their preferential interaction with the (100) plane (Pal, Tak \& Song, 
255 2007). In the case of aloe vera, a (111) plane of AgNPs predominantly arose as a major peak. This

256 plane was reported responsible for a strong antibacterial effect (Feng et al., 2000).

257 The factors controlling the morphology, size, and product purity in the hydrothermal process were

258 reaction temperature and time (Byrappa \& Adschiri, 2007; Liu et al., 2014). Moreover,

259 biosynthesis of inorganic nanoparticles with the plant extracts improved their bactericidal effect

260 (Yousefzadi, Rahimi \& Ghafori, 2014). High bactericidal activity was possibly caused by

261 synergistic antibacterial effects of AgNPs and naturally-occurring chemicals in aloe vera. The

262 lethal mechanism against pathogenic $S$. epidermidis and $P$. aeruginosa might involve the release

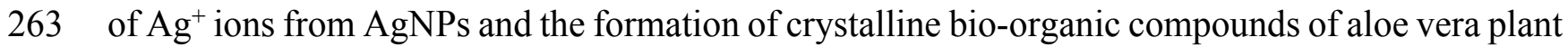

264 extract assembled with AgNPs anchored onto the bacterial cell walls, producing pits and

265 penetrating into the cytoplasm. Various natural ligands can interact with microbial membrane such

266 as saponin, tannin, terpenoids, and flavonoids in the aloe vera (Griffin et al., 1999; Sahu et al.,

267 2013). The interaction with the cell membrane may increase its permeability leading to cell lysis.

268 Moreover the free radicals from metal result in induction of oxidative stresses, such as reactive

269 oxygen species (ROS), that can damage the bacterial membranes, mitochondria, and DNA. This

270 eventually results in the death of the cell (Hajipour et al., 2012; Tamboli \& Lee, 2014). From our

271 results, a schematic mechanism involving the reaction of AgNPs@AV to kill the bacteria was

272 purposed and illustrated in Figure 6. Additionally, the susceptibility of different types of bacteria

273 was attributed to the structure of their bacterial cell walls. Previous studies indicated that the silver

274 ion released from AgNPs was responsible for antibacterial activity (Feng et al., 2000). The free

275 silver ion can then bind with the thiol groups of enzymes (Zhang et al., 2013). The AgNPs formed

276 at $100{ }^{\circ} \mathrm{C}$ for $6 \mathrm{~h}$ were found to be toxic to both gram-positive and gram-negative bacteria. This

277 might due to the smaller size of the AgNPs fabricated under these conditions which results a higher 
278 surface area (Cui et al., 2013). Silver ion release is a size dependent process (Cui et al., 2013). The

279 antibacterial activity of the synthesized AgNPs might be due to the silver ion release and the

280 resulting genotoxic activity of aloe vera on E. coli (Zhang et al., 2010). Interestingly, the samples

281 processed at $200{ }^{\circ} \mathrm{C}$ for $12 \mathrm{~h}$ had the largest size of those examined and they provided effective

282 growth inhibition of the pathogens. The results indicated that the larger AgNPs might contain high

283 levels of incorporated aloe vera compounds as well as a pure Ag phase due their long time and

284 high temperature treatment. Therefore, this hybrid nanostructure formed under specific conditions 285 can potential be an antibacterial agent.

287 Conclusion

288 This report described a green and facile method to synthesize AgNPs in large quantities. Silver 289 nitrate was reduced in an aloe vera plant-extract solution under a hydrothermal condition. Aloe 290 vera plant extract solutions were used as both reducing and stabilizing agents. Fine spherically 291 shape nanoparticles were obtained. The particle size of AgNPs can be tuned by varying the 292 hydrothermal temperature. The antibacterial effect of AgNPs@AV showed promise for use as a 293 highly potent agent with minimal cytotoxicity to human PBMCs. These hybrid nanomaterials 294 could potentially be used in biomedical applications.

\section{Acknowledgment}

297 The authors acknowledge the National Research University Project of Thailand, Office of the 298 Higher Education Commission, through the Advanced Functional Materials Cluster of Khon Kaen 299 University.

\section{References:}


302 Anker JN, Hall WP, Lyandres O, Shah NC, Zhao J, Van Duyne RP. 2008. Biosensing with 303 plasmonic nanosensors. Nature materials 7,442-453.

304 Byrappa K, Adschiri T. 2007. Hydrothermal technology for nanotechnology. Progress in Crystal Growth and Characterization of Materials 53,117-166.

Chandran SP, Chaudhary M, Pasricha R, Ahmad A, Sastry M. 2006. Synthesis of gold nanotriangles and silver nanoparticles using Aloevera plant extract. Biotechnology progress 22,577-583.

Cho K-H, Park J-E, Osaka T, Park S-G. 2005. The study of antimicrobial activity and preservative effects of nanosilver ingredient. Electrochimica Acta 51,956-960.

311 Chudasama B, Vala AK, Andhariya N, Mehta R, Upadhyay R. 2010. Highly bacterial resistant silver nanoparticles: synthesis and antibacterial activities. Journal of Nanoparticle Research 12,1677-1685.

314 Cui L, Chen P, Chen S, Yuan Z, Yu C, Ren B, Zhang K. 2013. In situ study of the antibacterial activity and mechanism of action of silver nanoparticles by surface-enhanced Raman spectroscopy. Analytical chemistry 85,5436-5443.

Emaga TH, Robert C, Ronkart SN, Wathelet B, Paquot M. 2008. Dietary fibre components and pectin chemical features of peels during ripening in banana and plantain varieties. Bioresource Technology 99,4346-4354.

Feng Q, Wu J, Chen G, Cui F, Kim T, Kim J. 2000. A mechanistic study of the antibacterial effect of silver ions on Escherichia coli and Staphylococcus aureus. Journal of biomedical materials research 52,662-668. 
323 Griffin SG, Wyllie SG, Markham JL, Leach DN. 1999. The role of structure and molecular

324 properties of terpenoids in determining their antimicrobial activity. Flavour and Fragrance

325 Journal 14,322-332.

326 Hajipour MJ, Fromm KM, Ashkarran AA, de Aberasturi DJ, de Larramendi IR, Rojo T, Serpooshan V, Parak WJ, Mahmoudi M. 2012. Antibacterial properties of nanoparticles. Trends in biotechnology 30,499-511.

Lee G-J, Shin S-I, Kim Y-C, Oh S-G. 2004. Preparation of silver nanorods through the control of temperature and $\mathrm{pH}$ of reaction medium. Materials Chemistry and Physics $\mathbf{8 4 , 1 9 7 - 2 0 4 . ~}$

Lee K-S, El-Sayed MA. 2006. Gold and silver nanoparticles in sensing and imaging: sensitivity of plasmon response to size, shape, and metal composition. The Journal of Physical Chemistry B 110,19220-19225.

Livermore DM. 2002. Multiple mechanisms of antimicrobial resistance in Pseudomonas aeruginosa: our worst nightmare? Clin Infect Dis 34(5),634-40.

Liu J, Sonshine DA, Shervani S, Hurt RH. 2010. Controlled release of biologically active silver from nanosilver surfaces. ACS nano 4,6903-6913.

Liu Z, Wang Y, Zu Y, Fu Y, Li N, Guo N, Liu R, Zhang Y. 2014. Synthesis of polyethylenimine (PEI) functionalized silver nanoparticles by a hydrothermal method and their antibacterial activity study. Materials Science and Engineering: C 42,31-37.

341 Liu Z, Xing Z, Zu Y, Tan S, Zhao L, Zhou Z, Sun T. 2012. Synthesis and characterization of 2005. The bactericidal effect of silver nanoparticles. Nanotechnology 16,2346. 
345 Nabikhan A, Kandasamy K, Raj A, Alikunhi NM. 2010. Synthesis of antimicrobial silver nanoparticles by callus and leaf extracts from saltmarsh plant, Sesuvium portulacastrum L. Colloids and Surfaces B: Biointerfaces 79,488-493.

Otto M. 2009. Staphylococcus epidermidis - the "accidental” pathogen. Nat Rev Microbiol 7(8),555-567.

Pal S, Tak YK, Song JM. 2007. Does the antibacterial activity of silver nanoparticles depend on the shape of the nanoparticle? A study of the gram-negative bacterium Escherichia coli. Applied and environmental microbiology 73,1712-1720.

353

Pradhan N, Pal A, Pal T. 2002. Silver nanoparticle catalyzed reduction of aromatic nitro compounds. Colloids and Surfaces A: Physicochemical and Engineering Aspects 196,247257.

Rai M, Deshmukh S, Ingle A, Gade A. 2012. Silver nanoparticles: the powerful nanoweapon against multidrug resistant bacteria. Journal of applied microbiology 112,841-852.

Rai M, Yadav A, Gade A. 2009. Silver nanoparticles as a new generation of antimicrobials. Biotechnology advances 27,76-83.

Rajan R, Chandran K, Harper SL, Yun S-I, Kalaichelvan PT. 2015. Plant extract synthesized silver nanoparticles: An ongoing source of novel biocompatible materials. Industrial Crops and Products 70,356-373.

Reynolds T, Dweck A. 1999. Aloe vera leaf gel: a review update. Journal of ethnopharmacology 68,3-37.

Sahu PK, Giri DD, Singh R, Pandey P, Gupta S, Shrivastava AK, Kumar A, Pandey KD. 2013. Therapeutic and medicinal uses of Aloe vera: a review. Pharmacology \& Pharmacy 4,599 . 
368 Sharma VK, Yngard RA, Lin Y. 2009. Silver nanoparticles: green synthesis and their 369 antimicrobial activities. Advances in colloid and interface science 145,83-96.

370 Sun Q, Cai X, Li J, Zheng M, Chen Z, Yu C-P. 2014. Green synthesis of silver nanoparticles

371

372

373

374

375

376

377

378

379

380

381

382

383

384

385

386

387

388

389

390 using tea leaf extract and evaluation of their stability and antibacterial activity. Colloids and Surfaces A: Physicochemical and Engineering Aspects 444,226-231.

Sun Y, Mayers B, Xia Y. 2003. Transformation of silver nanospheres into nanobelts and triangular nanoplates through a thermal process. Nano Letters 3,675-679.

Sun Y, Xia Y. 2002. Shape-controlled synthesis of gold and silver nanoparticles. Science 298,2176-2179.

Taleb A, Petit C, Pileni M. 1997. Synthesis of highly monodisperse silver nanoparticles from AOT reverse micelles: a way to $2 \mathrm{D}$ and $3 \mathrm{D}$ self-organization. Chemistry of Materials 9,950-959.

Tamboli DP, Lee DS. 2014. Mechanistic antimicrobial approach of extracellularly synthesized silver nanoparticles against gram positive and gram negative bacteria. Journal of hazardous materials 260,878-884.

Vazquez B, Avila G, Segura D, Escalante B. 1996. Antiinflammatory activity of extracts from Aloe vera gel. Journal of ethnopharmacology 55,69-75.

Yousefzadi M, Rahimi Z, Ghafori V. 2014. The green synthesis, characterization and antimicrobial activities of silver nanoparticles synthesized from green alga Enteromorpha flexuosa (Wulfen) J. Agardh. Materials Letters 137,1-4.

Zhang Y, Cheng X, Zhang Y, Xue X, Fu Y. 2013. Biosynthesis of silver nanoparticles at room temperature using aqueous aloe leaf extract and antibacterial properties. Colloids and Surfaces A: Physicochemical and Engineering Aspects 423,63-68. 
391 Zhang Y, Yang D, Kong Y, Wang X, Pandoli O, Gao G. 2010. Synergetic antibacterial effects

392 of silver nanoparticles@ aloe vera prepared via a green method. Nano Biomed Eng 2,252393257.

394 Zhang Z, Patel RC, Kothari R, Johnson CP, Friberg SE, Aikens PA. 2000. Stable silver 395 clusters and nanoparticles prepared in polyacrylate and inverse micellar solutions. The 396 Journal of Physical Chemistry B 104,1176-1182.

397 

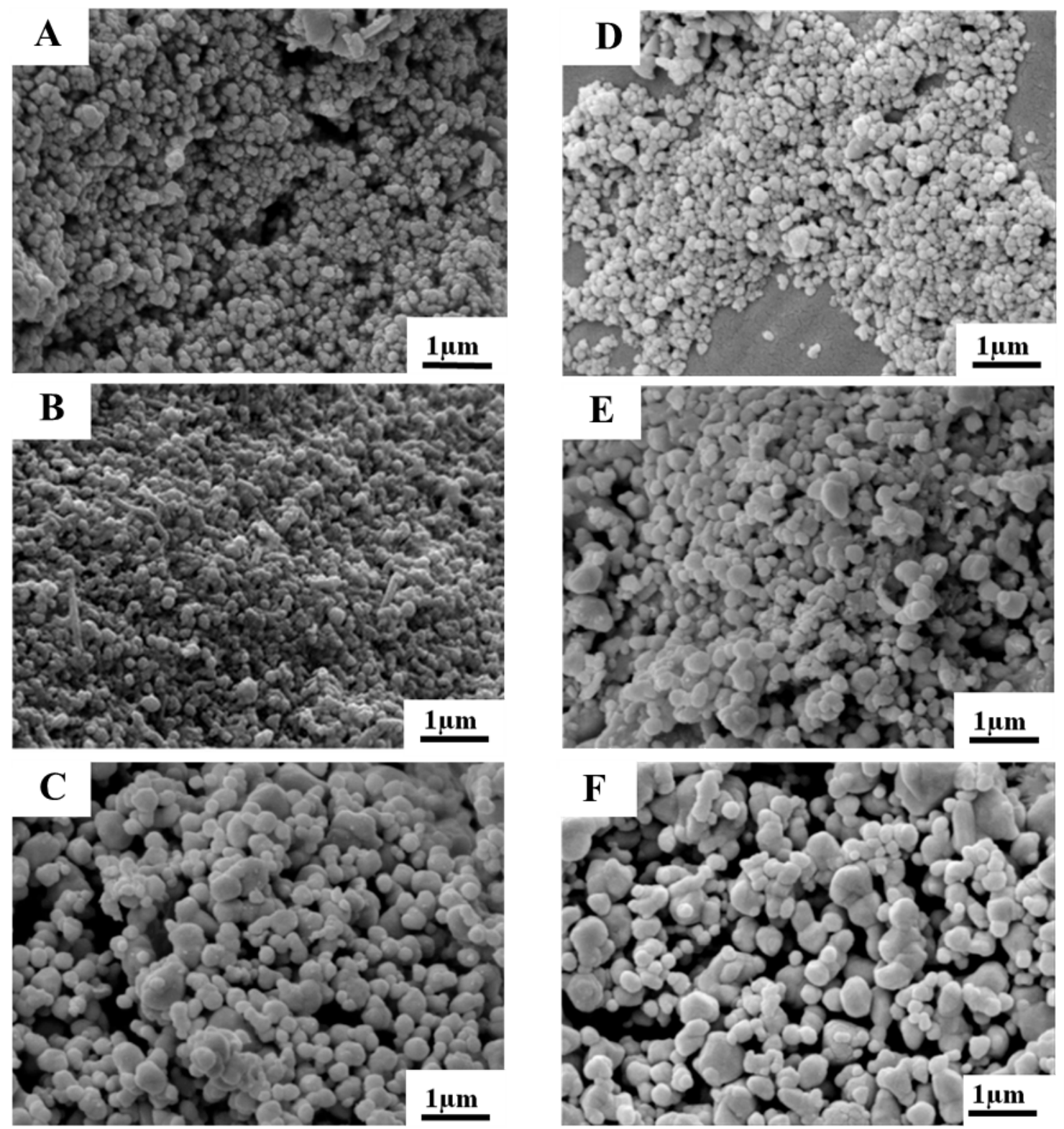

400 Figure 1 SEM images of silver nanoparticles on a glass slide after incubation at different

401 temperature and time combinations. SEM images of AgNPs were obtained at (A) $100{ }^{\circ} \mathrm{C}$ for

$4026 \mathrm{~h},(\mathrm{~B}) 150{ }^{\circ} \mathrm{C}$ for $6 \mathrm{~h},(\mathrm{C}) 200^{\circ} \mathrm{C}$ for $6 \mathrm{~h}$, (D) $100{ }^{\circ} \mathrm{C}$ for $12 \mathrm{~h}$, (E) $150{ }^{\circ} \mathrm{C}$ for $12 \mathrm{~h}$ and (F) 200

$403{ }^{\circ} \mathrm{C}$ for $12 \mathrm{~h}$. 
405

406

407

A

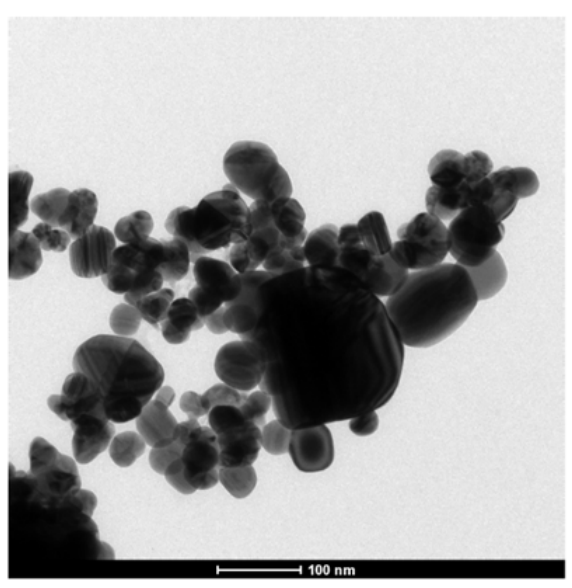

408

409

410

411

412

413

414

415

416

417

418

419

420

421

422

423

424

425

426

427

428

429

430

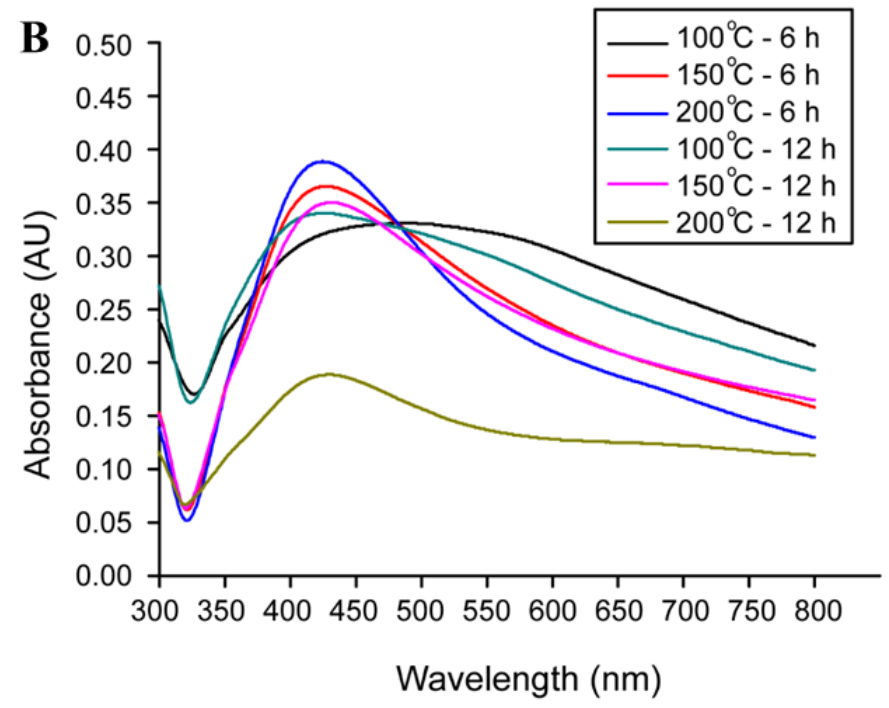

Figure 2 TEM image and UV-vis absorption spectra of AgNPs synthesized using an aloe vera

plant-extract solution. TEM image of AgNPs was obtained at $100^{\circ} \mathrm{C}$ for $6 \mathrm{~h}(\mathrm{~A})$ and UV-vis absorption spectra of AgNPs were shown in the maximum absorption at $420 \mathrm{~nm}$ (B). 
431

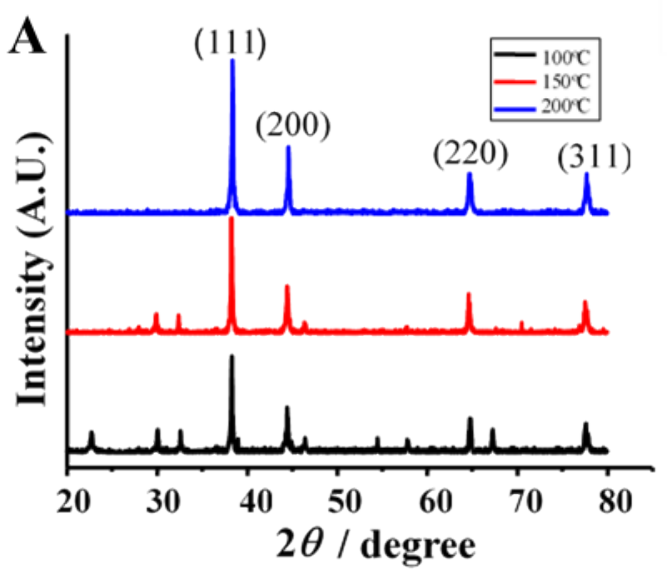

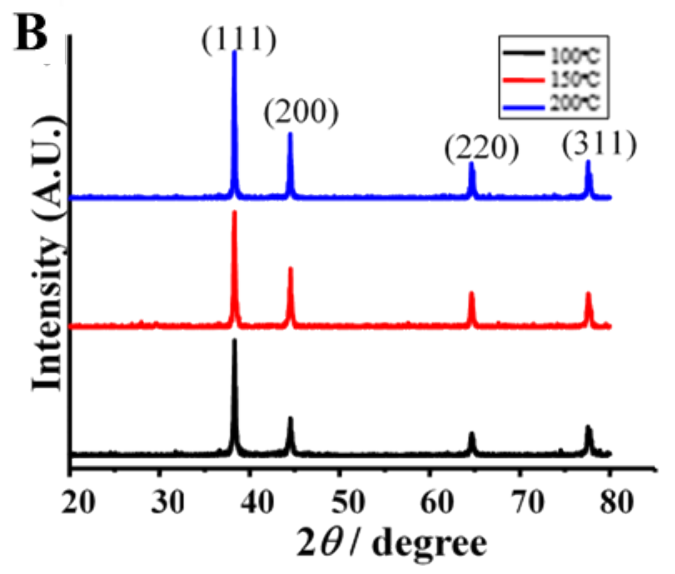

432

433 434 and (B) $12 \mathrm{~h}$.

435

436

437

438

439

440

441

442

443

444

445

446

447

448

449

450

451

452

453

454

455

456

457

458

459

460

Figure 3 XRD patterns of AgNPs synthesized using an aloe vera plant-extract solution. The AgNPs were prepared at temperatures of 100,150 , and $200{ }^{\circ} \mathrm{C}$ and for different times (A) $6 \mathrm{~h}$ 


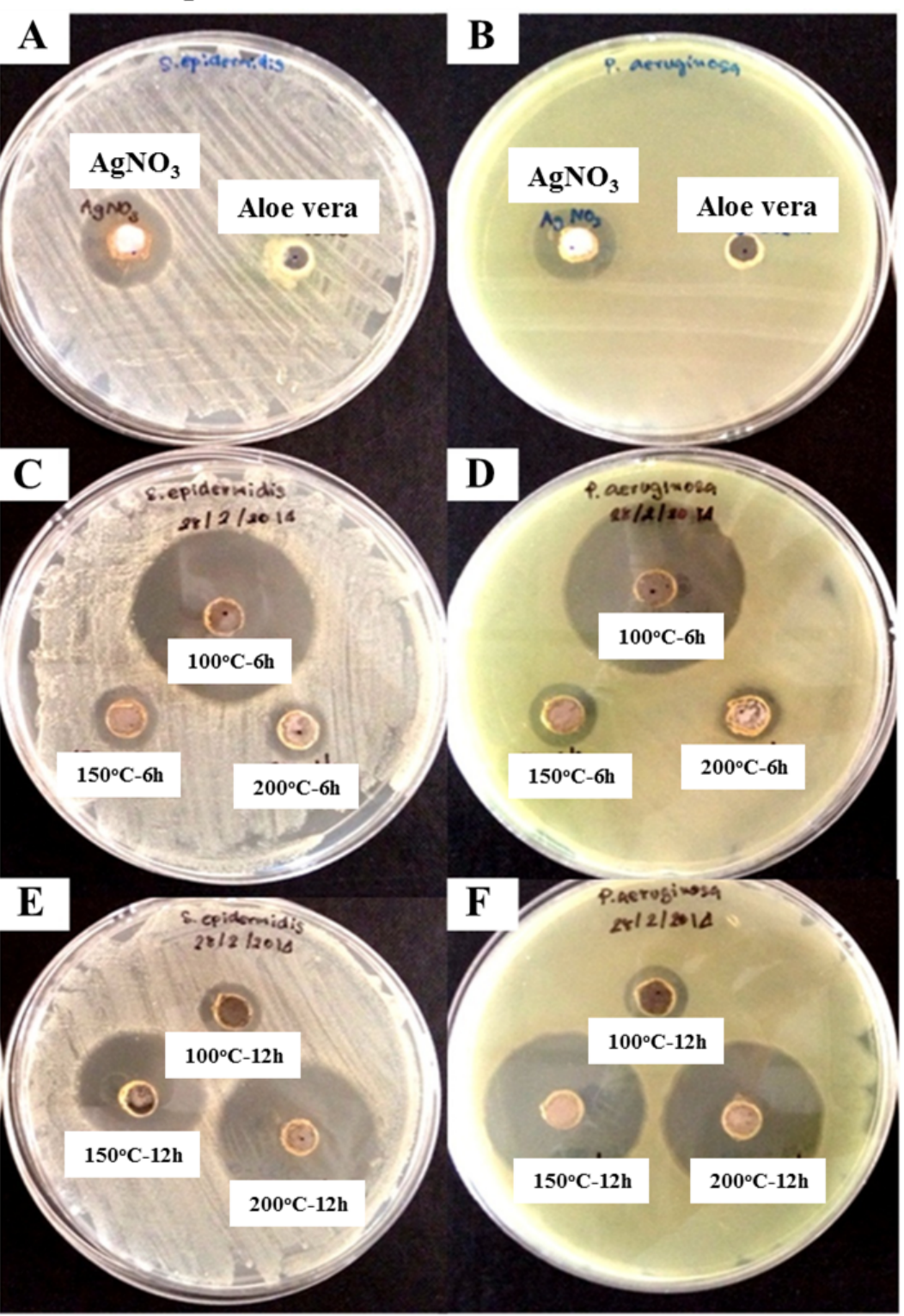

466 Figure 4 Antibacterial activity assay of AgNPs against $S$. epidermidis and $P$. aeruginosa. (A)

$467 \mathrm{AgNO}_{3}$ and aloe-vera extract control in S. epidermidis, (B) $\mathrm{AgNO}_{3}$ and aloe-vera extract control

468 in P. aeruginosa, (C) $100{ }^{\circ} \mathrm{C}-6 \mathrm{~h}, 150{ }^{\circ} \mathrm{C}-6 \mathrm{~h}$, and $200{ }^{\circ} \mathrm{C}-6 \mathrm{~h} \mathrm{AgNPs}$ at $(0.1 \mathrm{mg} / \mathrm{mL})$ in $S$.

469 epidermidis, (D) $100{ }^{\circ} \mathrm{C}-6 \mathrm{~h}, 150{ }^{\circ} \mathrm{C}-6 \mathrm{~h}$, and $200{ }^{\circ} \mathrm{C}-6 \mathrm{~h}$ AgNPs at $(0.1 \mathrm{mg} / \mathrm{mL})$ in

470 P. aeruginosa, (E) $100{ }^{\circ} \mathrm{C}-12 \mathrm{~h}, 150{ }^{\circ} \mathrm{C}-12 \mathrm{~h}$, and $200{ }^{\circ} \mathrm{C}-12 \mathrm{~h} \mathrm{AgNPs}$ at $(0.1 \mathrm{mg} / \mathrm{mL})$ in 
471 S. epidermidis, (F) $100{ }^{\circ} \mathrm{C}-12 \mathrm{~h}, 150{ }^{\circ} \mathrm{C}-12 \mathrm{~h}$, and $200^{\circ} \mathrm{C}-12 \mathrm{~h} \mathrm{AgNPs}$ at $(0.1 \mathrm{mg} / \mathrm{mL})$ in

472 P. aeruginosa.

473

474

475

476

477

478

479

480

481

482

483

484

485

486

487

488

489

490

491

492

493
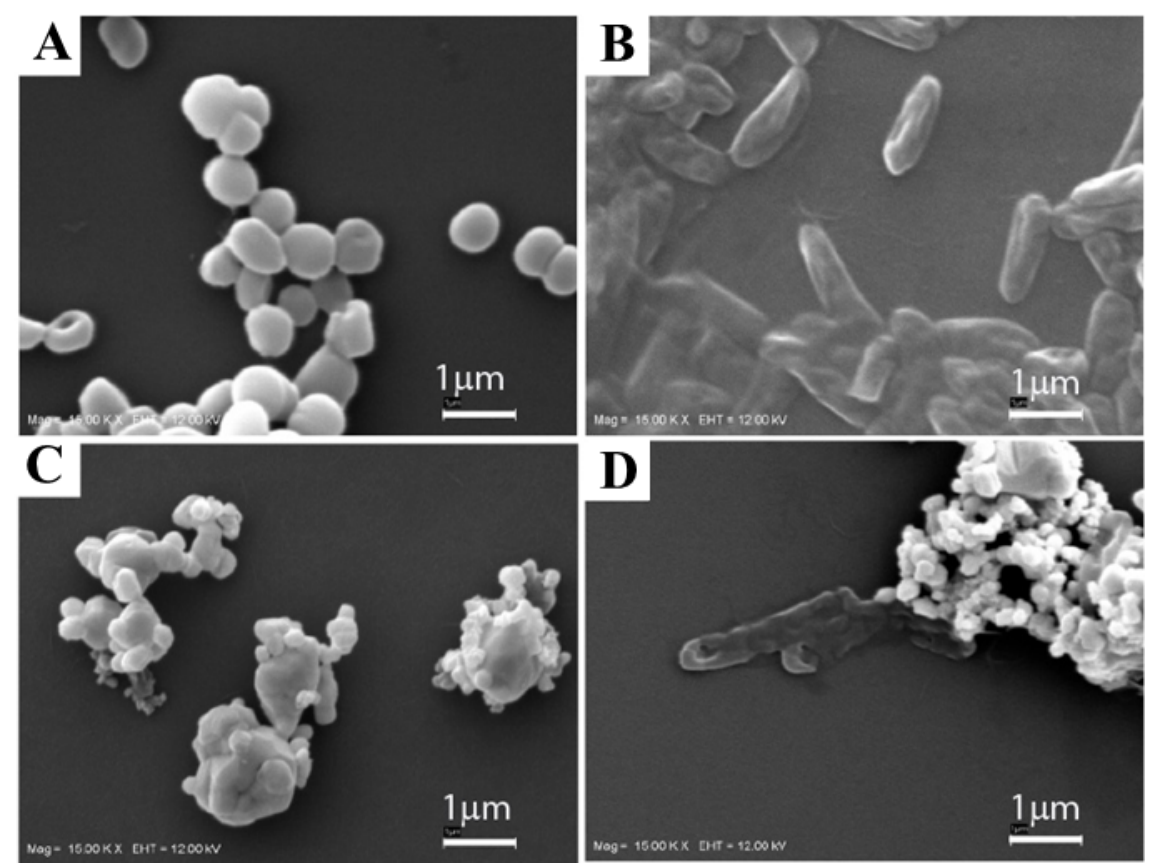

Figure 5 SEM images of the bacterial strains. (A) S. epidermidis, (B) P. aeruginosa,

(C) S. epidermidis treated with 100-6 h AgNPs (0.04 mg/mL), (D) P. aeruginosa treated with 100-6 h AgNPs (0.04 mg/mL). 


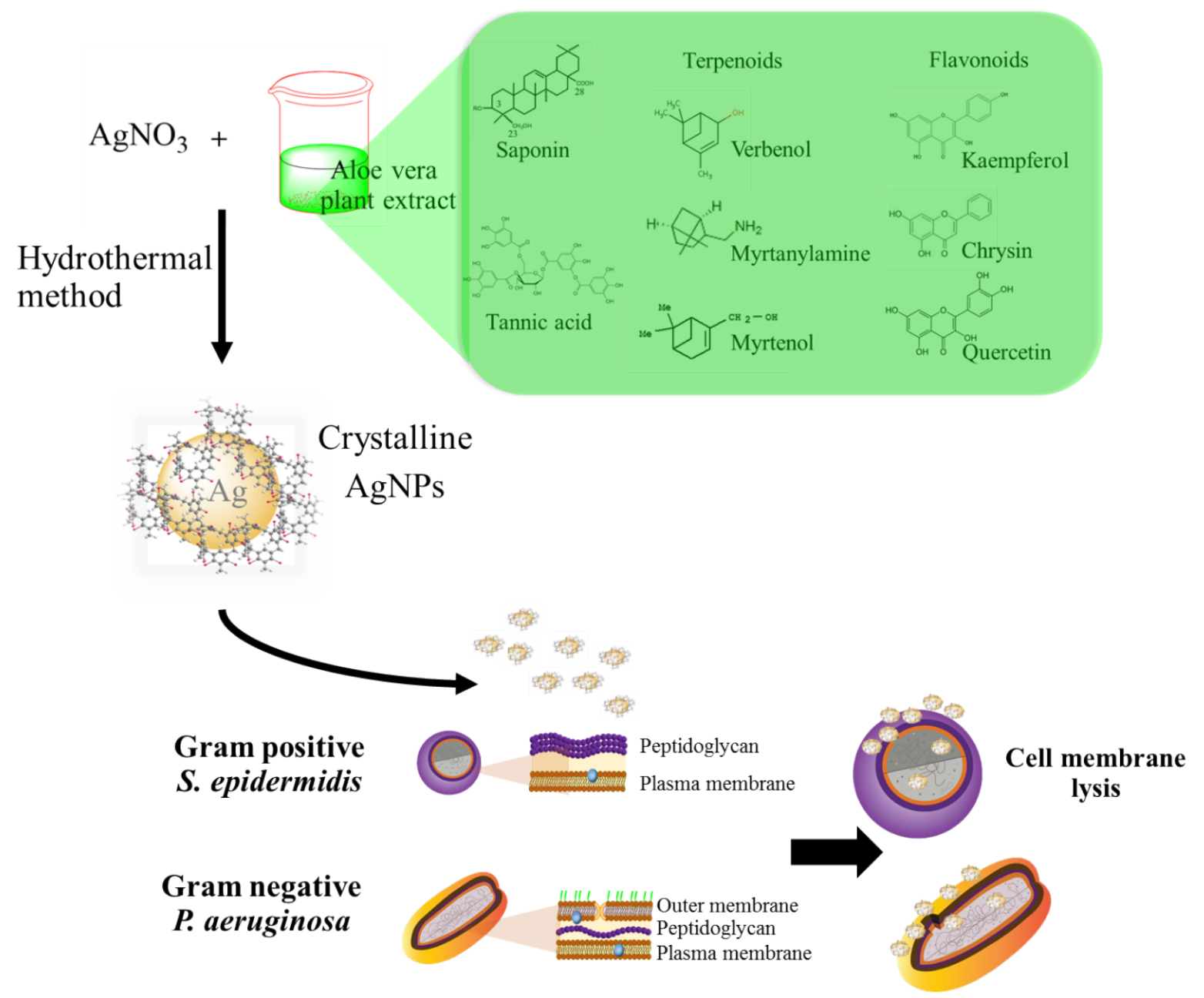

504 nanocrystalline AgNPs@AV to disrupt the bacterial membrane. In the hydrothermal method,

505 various organic compounds such as saponin, tannin, terpenoids, and flavonoids in the aloe vera

506 plant extract can be combined with $\mathrm{AgNO}_{3}$ synthesizing AgNPs@AV. These nanocrystals may 
507 accumulate at the cell membrane increasing its permeability, which eventually results in the death

508 of $P$. aeruginosa and $S$. epidermidis.

509

510 


\section{LIST OF TABLE CAPTIONS}

512 Table 1 Sizes of AgNPs and antibacterial efficiency of AgNPs in different hydrothermal

513 processes.

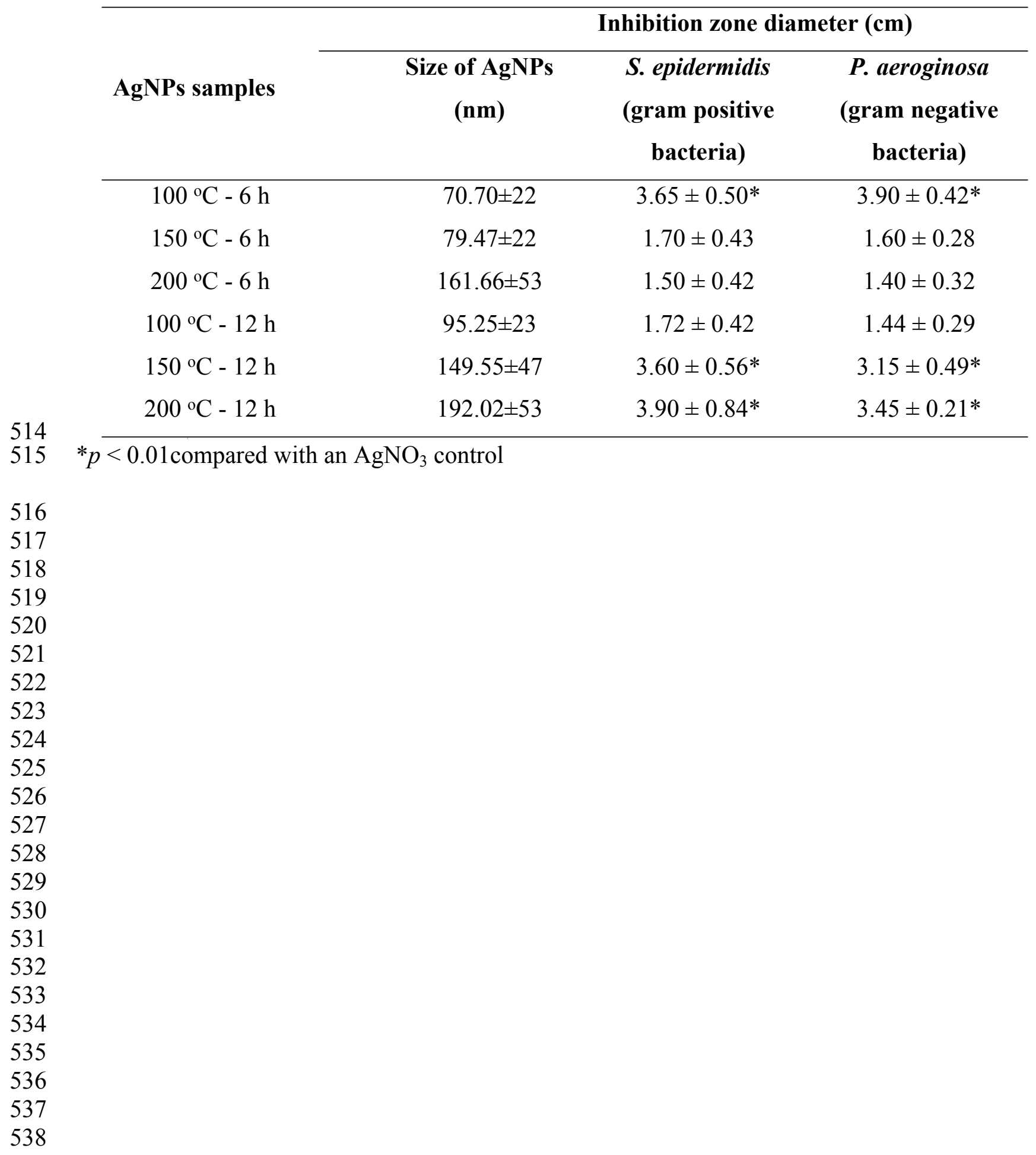


541 